\title{
Tendências e prioridades das pesquisas na saúde do idoso no contexto da enfermagem brasileira
}

\author{
Darlene Mara dos Santos Tavares
}

${ }^{1}$ Enfermeira, Doutora em Enfermagem. Professora Associado do Departamento de Enfermagem em Educação e Saúde Comunitária do Instituto de Ciências da Saúde da Universidade Federal do Triângulo Mineiro. Uberaba, MG, Brasil. E-mail: darlenetavares@enfermagem.uftm.edu.br.

O aumento do número de idosos e a maior longevidade vêm ocorrendo rapidamente no Brasil quando comparado aos países como França e Suécia. Se por um lado este fato representa uma conquista para a sociedade brasileira, por outro, traz novas demandas sociais ${ }^{(1)}$. Tais demandas expressam a necessidade de atender as especificidades desta população com vistas à manutenção da autonomia, independência e qualidade de vida.

Nesta perspectiva, a $\mathbf{W H O}^{(1)}$ apresentou proposições para a abordagem do envelhecimento saudável e ativo tais como a promoção da saúde e os comportamentos saudáveis em todas as idades para prevenir ou retardar o desenvolvimento de doenças crônicas; a diminuição das consequências de doenças crônicas por meio da deteç̧ão precoce e da qualidade dos cuidados, criando ambientes físicos e sociais que promovam a saúde e a participação dos idosos (acessibilidade, transporte, ligações inter-geracionais, atitudes sociais e organização do serviço) e a mudança de atitudes sociais para incentivar a participação dos idosos.

Buscando dar respostas às demandas sociais o Ministério da Saúde liderou a elaboração da Agenda Nacional de Prioridades de Pesquisa em Saúde de forma que a produção de conhecimentos e de bens materiais e processuais gerados nas áreas prioritárias pudesse contribuir com o desenvolvimento das políticas sociais ${ }^{(2)}$.

Dentre as 24 subagendas prioritárias a Saúde do Idoso contempla temas como: a magnitude, dinâmica e compreensão dos problemas de saúde do idoso, a compreensão dos mecanismos das doenças associadas ao processo de envelhecimento e a avaliação de políticas, programas, serviços e tecnologias ${ }^{(2)}$.

Consoante com as tendências internacionais e com o cenário nacional a Enfermagem também tem discutido coletivamente suas prioridades para o desenvolvimento de suas pesquisas ${ }^{(3)}$. Estudo apresentado no $17^{\circ}$. Seminário Nacional de Pesquisa em Enfermagem mostrou que para compor as prioridades de pesquisa em enfermagem partiu-se de 11 prioridades que caracterizam o campo de conhecimento da profissão. A reflexão aprofundada destas prioridades na especificidade do campo de enfermagem foi norteada pelo foco no cuidado, nos grupos populacionais, nos agravos nacionais, nas competências profissionais e nas temáticas priorizadas pela saúde ${ }^{(4)}$.

Desta forma, o referido estudo ${ }^{(4)}$ definiu cinco eixos transversais (Saúde, Ambiente, Trabalho e Biossegurança em Enfermagem; Avaliação de Tecnologias de Enfermagem e Economia da Saúde; Investigação Clínica em Enfermagem; Gestão do Trabalho e Educação em Saúde e Sistemas e Políticas de Saúde) e seis verticais subdivididos em três eixos temáticos de ações verticais (Cuidado de Enfermagem à Saúde Mental; Cuidado de Enfermagem as Doenças transmissíveis; Cuidado de Enfermagem as Doenças não-transmissíveis) e em três eixos temáticos por grupos populacionais (Cuidado de Enfermagem à Saúde do Idoso; Cuidado de Enfermagem à Saúde da Mulher; Cuidado de Enfermagem à Saúde da Criança e do Adolescente) ${ }^{(4)}$.

Considerando que o cuidado de enfermagem voltado para a saúde do idoso se constitui como uma entre as prioridades para a ciência da enfermagem, fez-se um levantamento que norteou algumas reflexões elaboradas nesse editorial.

A busca foi elaborada partindo-se dos artigos publicados na base de dados de Enfermagem (BDEnf) nos últimos 10 anos (2004 a 2013), utilizando as palavras idoso e enfermagem presentes no título, resumo e/ou descritores. Embora a BDEnf seja uma base até certo ponto restrita, ela congrega as revistas de enfermagem brasileiras indexadas, e o que interessava no momento era compreender o comportamento da produção da área sobre a temática saúde do idoso de modo mais geral.

O resultados desse exercício totalizou 593 artigos que foram lidos os resumos para verificar quais expressavam a temática de interesse. Após a leitura foram excluídos 20 (3,3\%) que estavam repetidos e 223 (37,6\%) que incluíam o adulto e/ou não tinham relação direta com o idoso, obtendo-se assim $350(59,1 \%)$ artigos. Dentre os artigos analisados destacam-se os temas mais prevalentes relacionados ao: cuidado de enfermagem direcionado ao idoso 30 $(8,5 \%)$; cuidadores de idosos $29(8,2 \%)$; diagnóstico de enfermagem direcionados a essa população $25(7,1 \%)$; 
idosos institucionalizados $25(7,1 \%)$; eram estudos relacionados a formação e qualificação do profissional de enfermagem na atenção ao idoso na percepção dos profissionais de enfermagem $23(6,5 \%)$; idoso hospitalizado 18 $(5,1 \%)$; capacidade funcional de idosos $13(3,7 \%)$; o idoso no contexto da família $13(3,7 \%)$, qualidade de vida de idosos $12(3,4 \%)$ e atividades educativas/grupos dirigidas a população idosa 10 (2,8\%).

Considera-se como limitação da análise o recorte temporal realizado na busca no banco de dados e também por ser a única base de objeto de análise. No entanto, a pretensão na composição do editorial era chamar a atenção para algumas lacunas que existem na área de enfermagem, no que diz respeito a saúde do idoso. Tais lacunas podem mobilizar o esforço dos pesquisadores, principalmente, aqueles vinculados aos programas de pós-graduação, de onde se originam a maior parte das pesquisas realizadas pela área no Brasil.

Fazendo uma reflexão sobre os apontamentos apresentados cabe considerar que os pesquisadores de enfermagem tem desenvolvidos seus trabalhos com aderência às prioridades expressas, contudo, tem-se ainda um amplo campo para investigação, no sentido de atender as especificidades da saúde do idoso. Observa-se que se constituem lacunas, por exemplo, os estudos voltados para a reorganização do cuidado de enfermagem na rede de atenção ao idoso com proposição de modelos de atenção; o desenvolvimento e/ou estabelecimento de tecnologias de cuidados de enfermagem que contribuam com a manutenção da autonomia, independência e qualidade de vida do idoso e familiares e para os cuidados de enfermagem de longa duração; a qualificação profissional de enfermagem e de cuidadores e proposição de indicadores de qualidade do cuidado de enfermagem.

Os artigos relacionados ao idoso desta edição abordam aspectos relevantes dos agravos de saúde que mais acometem esta população e ajudam a reflexão sobre as tecnologias de cuidado em enfermagem que tem potencial para ser implementado na prática profissional.

\section{REFERÊNCIAS}

1. World Health Organization. Good health adds life to years. Global brief for World Health Day 2012 [Internet]. Geneva: World Health Organization; 2012 [acesso em: 30 jun 2014]. Disponível em: http://whqlibdoc.who.int/hq/2012/WHO_DCO_WHD_2012.2_eng.pdf. 2. Ministério da Saúde. Agenda nacional de prioridades de pesquisa em saúde [Internet]. $2^{a}$ ed. Brasília: Ministério da Saúde; 2008 [acesso em: 30 jun 2014]. Disponível em: http://bvsms.saude.gov.br/bvs/publicacoes/AGENDA_PORTUGUES_MONTADO.pdf. 3. Oliveira DC. Prioridades de pesquisa em saúde e as áreas de conhecimento em enfermagem. Rev. enferm. UERJ [Internet]. 2013 [acesso em: 30 jun 2014];21(esp. 1):567-8. Disponível em: http://www.epublicacoes.uerj.br/index.php/enfermagemuerj/article/view/10062/7848.

4. Oliveira DC. Prioridades de pesquisa em saúde e em enfermagem. In: Anais do 170 Seminário Nacional de Pesquisa em Enfermagem, 2013 jun 3-5, Natal, Brasil [Internet]. Natal: Associação Brasileira de Enfermagem Seção Rio Grande do Norte; 2013 [acesso em: 30 jun 2014]. Disponível em: http://www.abeneventos.com.br/anais_senpe/17senpe/pdf/9018me.pdf. 